\title{
UM OLHAR SOBRE O SURGIMENTO E ASCENSÃO DO INTEGRALISMO NO SERTÃO DA BAHIA
}

\section{UNA MIRADA AL CRECIMIENTO Y LA ASCENSIÓN DEL INTEGRALISMO EN EL INTERIOR DE BAHIA}

\section{RESENHA}

Manoel Reinaldo Rego

Rede Municipal de Ensino de Vitória da Conquista

NETA, Amélia Saback Alves. Os verdes às portas do sertão: doutrina e ação política dos integralistas na Bahia (1932 - 1945). Salvador: Editora Saga, 2018. 170 páginas.

Com a possibilidade de ampliação das pesquisas em História, principalmente com o crescimento dos cursos de pós-graduação nesta área, vem surgindo, na Bahia, vários trabalhos sobre o povo sertanejo. Nesta perspectiva é que se enquadra o livro de Amélia Saback Neta.

O livro "Os verdes às portas do sertão" originalmente é fruto de uma dissertação de mestrado em História, apresentada na Universidade do Estado da Bahia, em 2011. Nela a autora aborda como os integralistas desenvolveram sua ação política em um momento em que várias disputas políticas e ideológicas se acirravam no Brasil. Este contexto é analisado principalmente a partir de duas cidades baianas - Serrinha e Alagoinhas.

Sendo fiel ao título, o trabalho em questão é uma vertente sobre os integralistas na Bahia, que adentraram no sertão, em Serrinha e Alagoinhas, não deixando de mencionar a atuação dos Integralistas em outras cidades baianas. A autora lança mão de várias formas de fontes para discorrer sobre a política integralista no sertão da Bahia, buscando compreender o conteúdo programático desta agremiação política, bem como suas ações no sentido de ampliar o quadro de militantes e melhorar a difusão de suas ideias.

O recorte cronológico utilizado, entre 1932 e 1945, compreende, na História do Brasil, o desdobramento e consolidação do governo Vargas e, na Bahia, a ascensão do Juracisismo

\begin{tabular}{|l|l|l|l|l|l|}
\hline Revista RBBA & ISSN 2316-1205 & Vitória da Conquista & V.8 $\mathrm{n}^{\circ} 2$ & p. 214-220 & Dezembro/2019 \\
\hline
\end{tabular}

Recebido em 25 de novembro de 2019. Aprovado em 12 de dezembro de 2019. 


\section{SERTÃO DA BAHIA}

como nova corrente política que se tornou uma das mais longevas deste Estado. O período estudado foi justificado pela pesquisadora, relacionando-o ao Manifesto Integralista de 1932, e o fim, em 1945, quando o fascismo europeu entrou em crise ao fim da Segunda Guerra Mundial e, no Brasil, os integralistas passaram a se aglutinar em outra agremiação partidária.

Amélia Saback faz, a partir da trajetória política e intelectual de alguns dos quadros do AIB (Ação Integralista Brasileira), um mosaico sobre o confronto ideológico e programático dos Camisas-Verdes no sertão da Bahia. O primeiro desses intelectuais é Rubem Nogueira, que se dedicava à atividade jornalística e partidária na capital e também no interior do estado, em Alagoinhas.

São perceptíveis no livro as primeiras ações do Governador Juracy Magalhães, com o intuito de convencer Getúlio Vargas do perigo que essa corrente política representava para o ideário da Revolução de 1930 na Bahia.

A obra, ao que parece, tinha como objetivo inicial abordar a formação e a movimentação da AIB nas cidades de Serrinha e Alagoinhas, e nas regiões circunvizinhas. Porém, demandas do trabalho levaram a pesquisadora a estender o estudo para várias cidades do interior do estado da Bahia. É nesse contexto que a autora aborda sobre os Integralistas no cenário da Segunda Guerra Mundial.

O livro "Os Verdes às portas do sertão" possibilita um entendimento de como Juracy Magalhães se posicionou durante esse período como Interventor e, posteriormente, governador eleito pela Assembleia Legislativa da Bahia. Menciona também uma vertente do contraditório afastamento, por renúncia, do referido político baiano, ligado a Getúlio Vargas, durante a proclamação do Estado Novo.

Outro fator que a obra em discussão menciona é o combate brando feito pelo governo baiano aos comunistas após o levante de 1935. Na maioria dos estados da federação os militantes do Partidão eram severamente combatidos e perseguidos após a frustrada tentativa de, juntamente com a ALN (Aliança Libertadora Nacional), destituir do poder Getúlio Vargas no referido ano. Porém, Juracy Magalhães estava preocupado, também, com a atuação dos Integralistas, principalmente seu adentramento ao interior do Estado.

Com isso, o pragmático político não se interessou pelo combate aos comunistas com as mesmas energias orientadas pelo poder central vindo do Rio de Janeiro. Assim, as duas agremiações políticas, os integralistas e os comunistas, que só tinham em comum a oposição 

SERTÃO DA BAHIA

ao juracisismo e seu PSD, encontraram um terreno fértil para campanhas de desmoralização recíproca.

Inclusive essa tese de acomodação dos comunistas por Juracy Magalhães na Bahia no início da década de 1930 já é mencionada pelo próprio político em seu livro de memória, “ $O$ último tenente", e por Patrícia Carneiro, no trabalho sobre a construção do juracisismo, fruto de sua dissertação de mestrado apresentada à Universidade Federal da Bahia (UFBA) em 2005. Aliás, a obra ora resenhada é um dos trabalhos a que Amélia recorre para abordar o tema.

Porém, é em "Impasse da Estratégia", de Carlos Zacarias de Sena Júnior, que se encontra uma explicação mais completa sobre a temática. Zacarias menciona que o impasse entre Vargas e os governadores do Nordeste já decorria por outros motivos. Além disso, o próprio Partido Comunista Brasileiro (PCB) vinha orientando a aproximação com os tenentes e interventores insatisfeitos com os rumos da Revolução de 1930.

Segundo esse autor, sobre a ação dos comunistas na tentativa de tomar o poder na Brasil em 1935, a Bahia tinha suas singularidades no contexto. Entre elas, estava o envolvimento de familiares do chefe do executivo estadual com a ALN, já que um irmão de Juracy chegou a responder Inquérito Policial Militar (IPM) acusado de participar do levante. Além disso, na Bahia houve poucos registros nos quais os comunistas desse estado estavam envolvidos com aqueles acontecimentos.

Para Juracy Magalhães, a força e o crescimento dos Integralistas no Estado que ele governava era o ponto de maior preocupação, a ponto de um entrevistado por Zacarias relatar que os Comunistas destituíram um palanque Integralista em Salvador (p. 53). Talvez, isso só aconteceu porque a força policial baiana fez vistas grossas na ocasião.

Eul So Pang, em um estudo clássico denominado de "Coronelismo e Oligarquias na Bahia (1889 a 1934)", é categórico em defender que a Revolução de 1930 só teve o efeito de disciplinar os coronéis dentro dos partidos políticos. Na verdade, é nessa nova forma de organização e disputa política no Pós-Revolução de 30 que Amélia concentra sua análise a partir de um partido, o Integralista.

Porém, a obra sobre os verdes nos conduz a um entendimento da movimentação dos principais grupos políticos baianos naquele contexto: O PSD, de Juracy Magalhães, o PCB, ligado a intelectuais e a setores da classe operária, os autonomistas, políticos que perderam o 


\section{SERTÃO DA BAHIA}

poder na Bahia com a chegada de Vargas ao Palácio do Catete no Rio de Janeiro. E, por último, a AIB, objeto de análise da autora.

Liderado por um quadro político oriundo da capital e do interior, que de certa forma não enquadrava em nenhuma das agremiações anteriores e elegeram os comunistas como principal alvo de combate, os integralistas, na grande maioria, eram pessoas que tinham atividades intelectuais na capital e que iam para o interior com objetivo de difundir a proposta e conquistar adeptos, organizando núcleos pelo sertão. Muitos desses intelectuais tinham sua origem em cidades sertanejas, sendo filhos de antigas lideranças políticas locais e a tarefa, com isso, era facilitada.

Como é explorado na literatura sobre a temática, as pesquisas clássicas tendiam a relacionar o Integralismo Brasileiro ao fascismo europeu. O livro "Os Verdes às Portas do Sertão" alonga ao avançar demonstrando que o fascismo brasileiro tem suas especificidades, a depender do local ou região. Além disso, as pesquisas clássicas muitas vezes concentram seu objeto nos grandes centros urbanos, em especial no Sul e Sudeste do Brasil.

No sentido inverso, caminhou a autora do livro hora resenhado. Amélia Saback atenta para um campo de estudo que ainda tem que ser muito pesquisado na história política brasileira: a ação dessa política de direita nas pequenas e médias cidades sertanejas.

O livro se torna importante para o contexto atual, na medida em que a autora mostra como o antipartidarismo, o antiliberalismo e o anticomunismo são a principal bandeira ideológica de uma agremiação política. Aliás, foram contra os comunistas que "os camisas verdes" tiveram mais efervescência em combater, em suas ações políticas.

Além do histerismo de os responsabilizarem por tudo de errado que acontecia, os comunistas sofriam acusações graves, desde questões ligadas à corrupção moral, ao fato de estarem a serviço de grupos estrangeiros (ser agente de Moscou). Outra coisa, que também é atual e foi utilizada na época, é a criminalização das oposições, no sentido de desmoralizá-las sem precisar de uma referência acusatória concreta.

Comenta Amélia Saback que esse procedimento de campanha de desmoralização dos adversários era uma tática constante dos Integralistas e das outras agremiações partidárias. Da mesma forma, é importante notar como os Integralistas defendiam uma bandeira ideológica a partir uma educação carregada de supostos valores morais e patrióticos, tão presentes no atual momento do país. 

SERTÃO DA BAHIA

O livro tem como principais fontes de análise jornais da época, como o serrinhense, o Momento, Seiva e o Imparcial. É perceptível, a partir da análise da autora, como as linhas editoriais desses jornais mudam de acordo com a conjuntura histórica do conturbado período entre Guerras e durante o momento beligerante.

De certa forma, este livro vem somar com outra obra, esta publicada pela EDUFA, Editora da Universidade Federal da Bahia em 2009, "Integralismo na Bahia: Gênero, Educação, e Assistência Social em o Imparcial 1933/1937”, que também é resultado de uma dissertação de Mestrado, desta feita de Laís Mônica Reis Ferreira, concluída na UFBA em 2006. A obra de Laís Mônica demonstra, principalmente a partir do jornal "O Imparcial”, como os integralistas desenvolveram a estratégia de difundir suas ideias e o espaço do poder na Bahia.

Alguns pontos diferem o trabalho das duas autoras. O primeiro deles é que Laís Mônica volta sua análise para a atuação da mulher no Movimento Integralista. A autora demonstra a contradição existente dentro da concepção da agremiação da AIB. Se por um lado os "camisas verdes" tinham um discurso antiliberal, por outro acabou defendendo posições do liberalismo ao defender a participação da mulher na política.

Porém, essa defesa era justificada pelos intelectuais deste partido, segundo eles, em razão da necessidade de as mães, esposas e noivas defenderem seus maridos, noivos e namorados das garras do comunismo que queria profanar o Brasil. Com isso, as mulheres tornavam-se as guardiãs da família e da Pátria.

Outro ponto abordado pela autora, no que se refere à atividade das mulheres na atuação do partido, é a prática assistencialista fundamentada na caridade. Aliás, essa prática já era bem conhecida pelas famílias na sociedade conservadora voltada para uma caridade orientada pela Igreja Católica. Laís Mônica menciona em sua abordagem que os Integralistas tinham em seu foco as camadas populares da sociedade baiana, ponto que não foi explorado por Amélia Saback.

Porém, há um argumento em comum entre as duas autoras: a interiorização do movimento integralista, que, por várias razões, não via somente a capital como possibilidade de ação. Entre estes motivos estava a concorrência com as outras agremiações.

Talvez tenha sido isso que causou uma das grandes rivalidades com Juracy Magalhães, que, diferentemente das maiores lideranças expressivas da Bahia antes de 1930, 


\section{SERTÃO DA BAHIA}

não percorria o sertão fazendo alianças com pequenos e médios líderes políticos: os coronéis menos expressivos.

Voltando ao "Os verdes às portas do sertão", trata-se de obra com 170 páginas e foi organizado em três capitulo. No primeiro capítulo, Amélia Sabak apresenta as ações políticas dos Integralistas rumo ao Sertão e seu confronto ideológico com os liberais e comunistas. Nesse capítulo, a autora concentra sua análise, principalmente, em duas cidades: Alagoinhas e Serrinha.

O segundo capítulo, intitulado “A província Mártir no Integralismo”, a autora aborda o crescimento dos integralistas no interior do estado da Bahia e o que levou Juracy Magalhães a modificar seu olhar sobre essa agremiação política. Se em 1933 o antigo interventor os via com simpatia, a partir das eleições de 1936 seu olhar sofre uma guinada. As ações dos integralistas passaram a ter um acompanhamento, com perseguição por parte da polícia baiana.

No terceiro capítulo, que a autora denominou de "verso e revesso da história: produção da memória comunista acerca do integralismo" é o momento em que Amélia utiliza a produção dos comunistas como fonte de análise do integralismo. Ela aborda como os jornais "Seiva" e "O Momento", ligados ao partido comunista, começam a fazer campanha de desmoralização dos camisas verdes. Essas revistas eram espaço reservado à intelectualidade baiana, com objetivo de fazer críticas e combates ao fascismo.

Além disso, a autora utiliza como fonte obras de cunho memorialistas dos comunistas, como é o caso do livro "O partido comunista que eu conheci", de João Falcão, e o livro de Jorge Amado "Farda, fardão, camisola de dormir".

É também neste último capítulo, o mais extenso, que a autora analisa o combate aos integralistas no período da Segunda Guerra Mundial. Utilizando-se da memória deixada por comunistas, e principalmente usando jornais como fonte, Amélia discorre sobre a atuação dessa intelectualidade na desmoralização dos "Camisas Verdes" e seus séquitos, merecendo a pena utilizada por Jorge Amado nos jornais ligados ao PCB.

Ao ler a obra de Amélia, percebe-se o processo de continuidade e atualidade no comportamento político do brasileiro de nossos dias. Por exemplo, quando vimos a atuação dos movimentos de extrema-direita, como MBL e Vem Pra Rua, no processo de Impedimento de Dilma Lana Rousseff, elegendo a camisa amarela como a indumentária de protesto, leva- 

SERTÃO DA BAHIA

nos a concluir que esses grupos políticos não podem ser considerados uma "onda conservadora" como muito os denominam. Em verdade, trata-se de um processo de continuidade e reinvenção de uma extrema direita que ressurge em contextos de crises políticas.

\section{Sobre o autor}

Manoel Reinaldo Silva Rego é Licenciado em História pela Universidade Estadual do Sudoeste da Bahia (UESB) e professor de História da Rede Municipal de Ensino de Vitória da Conquista. Atualmente cursa o Mestrado Acadêmico em História Social pela Universidade Federal da Bahia (UFBA).

Endereço eletrônico: msilvarego6@gmail.com 